ARTICLE

Received 9 Mar 2015 | Accepted 21 May 2015 | Published 2 Jul 2015

DOI: $10.1038 /$ ncomms 8589

OPEN

\title{
Determining the location and nearest neighbours of aluminium in zeolites with atom probe tomography
}

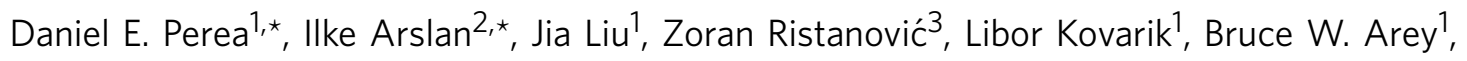
Johannes A. Lercher ${ }^{2,4}$, Simon R. Bare ${ }^{5} \&$ Bert M. Weckhuysen ${ }^{3}$

Zeolite catalysis is determined by a combination of pore architecture and Brønsted acidity. As Brønsted acid sites are formed by the substitution of $\mathrm{AlO}_{4}$ for $\mathrm{SiO}_{4}$ tetrahedra, it is of utmost importance to have information on the number as well as the location and neighbouring sites of framework aluminium. Unfortunately, such detailed information has not yet been obtained, mainly due to the lack of suitable characterization methods. Here we report, using the powerful atomic-scale analysis technique known as atom probe tomography, the quantitative spatial distribution of individual aluminium atoms, including their three-dimensional extent of segregation. Using a nearest-neighbour statistical analysis, we precisely determine the short-range distribution of aluminium over the different T-sites and determine the most probable Al-Al neighbouring distance within parent and steamed ZSM-5 crystals, as well as assess the long-range redistribution of aluminium upon zeolite steaming.

\footnotetext{
${ }^{1}$ Pacific Northwest National Laboratory, Environmental Molecular Science Laboratory, 3335 Innovation Boulevard, Richland, Washington 99352, USA.

${ }^{2}$ Pacific Northwest National Laboratory, Institute for Integrated Catalysis, 902 Battelle Boulevard, Richland, Washington 99352, USA. ${ }^{3}$ Faculty of Science, Debye Institute for Nanomaterials Science, Utrecht University, Universiteitsweg 99, Utrecht 3584 CG, The Netherlands. ${ }^{4}$ Department of Chemistry, TU Munich, Lichtenbergstrasse 4, Garching 85748, Germany. ${ }^{5}$ UOP LLC, a Honeywell Company, 25 E. Algonquin Road Des Plaines, Illinois 60016, USA. * These authors contributed equally to this work. Correspondence and requests for materials should be addressed to S.R.B. (email: simon.bare@honeywell.com) or to B.M.W. (email: b.m.weckhuysen@uu.nl).
} 
Z eolites are microporous crystalline aluminosilicates that find widespread application in the chemical and petrochemical industry, for example, as a workhorse in the catalytic cracking of heavy crude oil fractions to make gasoline and propylene. More recently, zeolite-based catalysts have found their way in the transformation of alternative feedstocks, such as biomass and natural gas. Aluminium is the key element that introduces negative charge into the framework of zeolite, which is often counterbalanced by protons leading to the formation of Brønsted acid sites that are responsible for catalytic activity. Another example of important Al-related species in zeolites include Lewis acid sites, and extra-framework metal cations that are coordinated to $\mathrm{Al}$ atoms in zeolites ${ }^{1}$. Concentration (often expressed as $\mathrm{Si} / \mathrm{Al}$ ratio) and precise location of $\mathrm{Al}$ in the zeolite framework determine the number and strength of these acid sites ${ }^{2}$ and have detrimental effects on the success of various post-treatment methods that aim to improve molecular transport through the zeolite crystals, such as desilication and dealumination ${ }^{3,4}$.

The inhomogeneous distribution of $\mathrm{Al}$ within zeolites has been noted in numerous occasions and depends on the type of zeolite framework, Si/Al ratio, crystal size and synthesis parameters ${ }^{5}$ leading to distinct $\mathrm{Al}$ distributions that are characterized by either short-range ( $\mathrm{T}$-site distribution) or long-range (zoning or extra-framework) lengthscales. The unit cell of the industrially important zeolite ZSM-5 (refs 6-8) has 12 distinct crystallographic $\mathrm{T}$-sites $^{9-11}$. Using techniques, such as X-ray diffraction, the distribution of $\mathrm{Al}$ atoms over specific $\mathrm{T}$-sites is difficult to determine due to low scattering contrast between $\mathrm{Si}$ and $\mathrm{Al}$. However, X-ray diffraction studies that include ion-exchanged Cs-ZSM-5 and Tl-ZSM-5 zeolites have shown a non-random $\mathrm{Al}$ distribution over crystallographic T-sites ${ }^{12,13}$. Correspondingly, Al nuclear magnetic resonance (NMR) studies suggest that the $\mathrm{Al}$ distribution over the $\mathrm{T}$-sites is kinetically controlled and not random, while the distribution can vary substantially according to the conditions of zeolite synthesis ${ }^{14,15}$. A recent study by Vjunov et al. ${ }^{16}$ confirms that identical zeolite types may have drastically different $\mathrm{Al}$ distribution over T-sites. Unfortunately, to date, the fundamental question as to the precise distribution of $\mathrm{Al}$ as a function of synthesis and how the distribution may change after processing remains elusive.

Another distinct type of $\mathrm{Al}$ distribution is commonly known as $\mathrm{Al}$ zoning and describes the long-range heterogeneous distribution of Al. Several studies have shown heterogeneous surface and bulk distribution of $\mathrm{Al}$ within individual zeolite ZSM-5 crystals ${ }^{17-22}$. Post-synthesis processing to either stabilize/ activate or deactivate the ZSM-5 also affects the long-range Al distribution through dealumination-a process in which aluminium is expelled from the framework structure in the presence of, for example, steam, leading to the generation of extra-framework $\mathrm{Al}^{23}$. It is often speculated that the number and coordination of extra-framework Al species play a significant role in acid-catalysed reactions ${ }^{24-26}$.

Current characterization tools for studying the spatial distribution of $\mathrm{Al}$ in zeolites are scarce. Most of the methods rely on the bulk characterization of $\mathrm{Si}$ and $\mathrm{Al}$ coordination. The major drawback of bulk characterization methods is the averaging over the whole crystalline bulk, while any atomic-scale variation in the distribution of $\mathrm{Al}$ goes undiscovered. For example, solid-state ${ }^{27} \mathrm{Al}$ MAS NMR can provide detailed information about $\mathrm{T}-\mathrm{O}-\mathrm{T}$ angle and chemical nature of $\mathrm{Al}$ species ${ }^{27}$; however, the signal is averaged over the crystalline bulk and the analysis of T-site distribution still remains a difficult task. Furthermore, $\mathrm{X}$-ray and electron probe-based techniques give no distinguishable contrast between $\mathrm{Si}$ and $\mathrm{Al}$ making highresolution analysis very challenging. X-ray absorption fine structure analysis in combination with NMR was recently used to quantitatively probe bulk distribution of $\mathrm{Al}$ over $\mathrm{T}$-sites in $\mathrm{H}-\beta$ zeolite $^{16}$. Other X-ray absorption fine structure studies have been used to determine in situ structural changes of $\mathrm{Al}$ coordination in various zeolite topologies ${ }^{28-32}$. X-ray standing waves have been applied as a method to determine $\mathrm{T}$-position of $\mathrm{Al}$ in extremely large crystals of zeolite scolecite ${ }^{33}$, while X-ray tomography in the soft X-ray regime has allowed spatial mapping of aluminium in zeolite ZSM-5, but with a limited spatial resolution of $\sim 30 \mathrm{~nm}$ (refs 34,35). X-ray photoelectron spectroscopy $^{20,36,37}$ and energy-dispersive X-ray spectroscopy ${ }^{19}$ are often used to provide surface and bulk characterization of $\mathrm{Si} / \mathrm{Al}$ ratio and coordination of $\mathrm{Al}^{37}$ with penetrating depths of about $10 \mathrm{~nm}$ and $1 \mu \mathrm{m}$, respectively.

It is clear that the spatial placement of $\mathrm{Al}$ in zeolite materials is still unknown as the characterization tools that can spatially resolve the distribution of $\mathrm{Al}$ in zeolites are lacking. Here we present a unique characterization approach, which involves the combination of well-defined zeolite ZSM-5 crystals and a powerful nanoscale probing method, namely atom probe tomography (APT). APT is a three-dimensional (3D) compositional mapping technique based on the field evaporation, time-of-flight detection and $3 \mathrm{D}$ reconstruction of individual atoms (ions) from the tip of a needle-shaped specimen ${ }^{38}$. APT is used to quantitatively determine the $3 \mathrm{D}$ distribution and extent of aggregation of individual $\mathrm{Al}$ atoms within parent and steam-treated ZSM-5 crystals. Not only can we precisely determine the short-range distribution of $\mathrm{Al}$ over the different $\mathrm{T}$-sites in both sets of materials and determine the most probable $\mathrm{Al}-\mathrm{Al}$ neighbouring distance, but we can also assess the long-range $\mathrm{Al}$ redistribution upon zeolite steaming.

\section{Results}

FIB-based specimen preparation for APT analysis. For a complete description of the ZSM-5 crystal synthesis and related steam treatment used in this study, we refer the reader to ref. 36. In what follows, we will refer to ZSM-5-P and ZSM-5-ST when discussing, respectively, the parent and severely steam-treated ZSM-5 crystals under study. The typical morphology of the two sets of ZSM-5 crystals is shown in Fig. 1a, which exhibit a coffin-like geometry and $\sim 20 \times 20$ $\times 100 \mu \mathrm{m}^{3}$ dimensions. We note that no distinguishable difference in the bulk morphology between both ZSM-5-P and ZSM-5-ST was observed when imaged via helium ion microscopy or scanning electron microscopy (SEM) at a nominal spatial resolution of $\sim 1 \mathrm{~nm}$.

To prepare specimens from a portion of individual ZSM-5 crystals into the needle-like geometry necessary for APT analysis, a dual-beam focused ion beam/scanning electron microscope (FIB/SEM) was used. In brief, an electron beam and ion beam deposited a Pt/C cap of dimensions $2 \times 30 \mu \mathrm{m}^{2}$ with $\sim 500 \mathrm{~nm}$ total thickness centred longitudinally, which protects the underlying region of interest from unintentional Ga-ion damage during trenching to form a lamellar structure (Fig. 1b). An OmniProbe nanomanipulator was then attached to the lamella and it was lifted out (Fig. 1c), and $\sim 2-3 \mu \mathrm{m}$ portion was positioned on a $\mathrm{Si}$ micropost structure (Fig. 1d,e). Using an annular milling pattern, the specimen was milled into a needle-like shape with a final tip radius curvature of $\sim 50 \mathrm{~nm}$ (Fig. 1f). Note that from a single lamella $30 \mu \mathrm{m}$ long, $\sim 9-11$ individual microposts can be populated and shaped into needles for analysis. Before loading the specimen substrate into the atom probe, a thin $\mathrm{Cr}$ film $\sim 20 \mathrm{~nm}$ thick was deposited uniformly to the surface of the specimen to increase the specimen evaporation/yield during APT analysis ${ }^{39}$. 

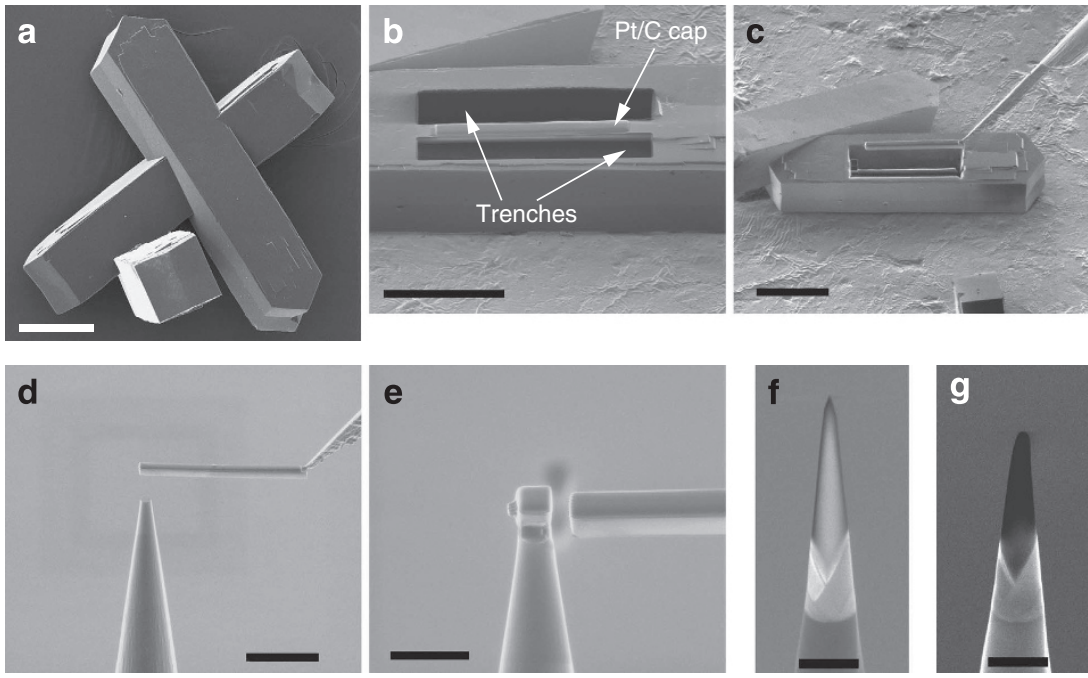

Figure 1 | FIB-based preparation of specimens for APT analysis. (a) Helium ion microscope image of typical coffin-shaped zeolite ZSM-5 crystals under study. Scale bar, $20 \mu \mathrm{m}$. (b) First step in the APT specimen preparation using the FIB-SEM approach: trenching of lamellar wedge with a protective Pt cap. Scale bar, $20 \mu \mathrm{m}$. (c) Lift-out. Scale bar, $25 \mu \mathrm{m}$. (d,e) Attachment to Si micropost. Scale bar, 15 and $5 \mu \mathrm{m}$, respectively. (f) Final specimen morphology with tip diameter of $\sim 100 \mathrm{~nm}$. (g) Same tip shown in $\mathbf{f}$ but after APT analysis. An estimate of the analysed volume is made by comparison of $\mathbf{f}, \mathbf{g}$. Scale bar for $\mathbf{f}, \mathbf{g}), 500 \mathrm{~nm}$

Maintaining the crystallinity of the ZSM-5 sample was found to be relatively sensitive to the Ga-ion beam current. A high ion beam current of $1 \mathrm{nA}$ at $30 \mathrm{kV}$ during the trenching of specimen wedge (Fig. 1b) resulted in a fully amorphized structure as shown in Supplementary Fig. 1a-c. Using a relatively low ion beam current of $240 \mathrm{pA}$ at $30 \mathrm{kV}$ during the trenching resulted in a mostly crystalline structure as shown in Supplementary Fig. 1d,e. Interestingly, at the lower ion beam current, we consistently found an amorphous 'shell' surrounding a crystalline core (Supplementary Fig. 1d). The thickness of the amorphous region between the $\mathrm{Pt} / \mathrm{C}$ cap and crystalline core ranged from $\sim 40$ to $100 \mathrm{~nm}$, while the amorphous layer thickness on the surface ranged between $\sim 5$ and $20 \mathrm{~nm}$. With both the high and low ion beam current cases, the same $2 \mathrm{kV}$ exposure was used to remove the damaged surface layer (see Thompson et al. ${ }^{40}$ ) and so we conclude that this low $\mathrm{kV}$ exposure did not result in amorphization; rather, the tendency to fully amorphize was sensitive to the ion beam current during the trenching step.

APT of parent and severely steamed-treated ZSM-5 crystals. APT allows both a qualitative and quantitative analysis. Qualitatively, the distribution of $\mathrm{Al}$ within the ZSM-5-P crystal is found to be homogeneous as shown in Fig. 2. A mass spectrum is shown in Fig. 2a where both $\mathrm{Si}$ and $\mathrm{O}$ are observed as the major species, with Si detected as singly, doubly and triply charged ions. Complex ions made up of $\mathrm{Si}$ and $\mathrm{O}$ are also observed, for example, $\mathrm{O}_{2}^{+}, \mathrm{SiO}^{2+}$ and $\mathrm{SiO}_{2}^{+}$.

We also observe distinct $\mathrm{C}$ peaks in the mass spectrum. We can only speculate as to the origin of $\mathrm{C}$ as being either a remnant of the synthesis and subsequent calcination process or simply adsorbed hydrocarbons from air during sample handling. The presence of $\mathrm{Al}$ is shown in the zoomed in mass spectrum of Fig. 2b. Note that the mass resolution is high enough to easily distinguish the three individual isotopes of Si from monoisotopic Al. The tomographic reconstruction qualitatively shows a homogeneous distribution of $\mathrm{Si}$ and $\mathrm{O}$ (Fig. 2c) as well of $\mathrm{Al}$ (Fig. 2d), where each sphere represents the three-dimensional position of an individual colour-coded atom.
In stark contrast, the $\mathrm{Al}$ distribution in the severely steam-treated ZSM-5 crystal is found to be very heterogeneous, with regions of high $\mathrm{Al}$ concentration. The $3 \mathrm{D}$ atom maps of ZSM-5-ST in Fig. 3a,b display the distribution of $\mathrm{Si}, \mathrm{O}$ and $\mathrm{Al}$, respectively. Visually, the $\mathrm{Si}$ and $\mathrm{O}$ distribution is homogeneous and similar to that found in Fig. 2a for ZSM-5-P. However, the Al distribution shows a visually clear heterogeneous distribution with $\mathrm{Al}$ tending to form local regions of high $\mathrm{Al}$ concentration. In addition, we observe both the ion-sputtered $\mathrm{Cr}$ coating and a remnant of the FIB-deposited protective Pt capping layer that was not completely removed during the final FIB-milling. The presence of both the $\mathrm{Cr}$ and $\mathrm{Pt}$ does not negatively affect the analysis; rather, the Pt specifically provides a very important fiducial marker for quantitative compositional depth profiling relative to the initial exposed surface of the steam-treated zeolite.

In Fig. 3c, the Si/Al ratio (green) is plotted as a function of distance from the surface; the surface is marked by the horizontal dashed line below the Pt layer. Large fluctuations in the ratio are observed and arise from atomic deviations in the distribution within the 1-nm bins. Using a least-squares polynomial fit (green dashed curve), the $\mathrm{Si} / \mathrm{Al}$ ratio shows a maximum of 140 at a depth of about $50 \mathrm{~nm}$. We note that the unintentional implantation of Ga (Fig. 3c) during the Pt deposition has the potential to affect the Al distribution. However, it seems that any perturbation from $\mathrm{Ga}$ to the $\mathrm{Si} / \mathrm{Al}$ ratio measured here is not significant considering our results are consistent with a previously published $\mathrm{Si} / \mathrm{Al}$ ratio determined from X-ray photoemission spectroscopy depth profiling of the same steamed ZSM-5-ST sample ${ }^{36}$.

The individual particle-to-particle reproducibility of $\mathrm{Al}$ distribution in both ZSM-5-P and ZSM-5-ST as measured by APT analysis is established in the $3 \mathrm{D}$ reconstructions shown in Supplementary Fig. 2 for different specimens of the same ZSM-5 material. A visually homogeneous distribution of $\mathrm{Al}$ within the parent ZSM-5 has been observed, while Al clustering was apparent in the severely steam-treated ZSM-5, consistent with the analysis described in Fig. 2 and Fig. 3, respectively. Note that the protective Pt cap is not observed (such as the case in Fig. 3), and so the depth of the analysis relative to the exposed surface is unknown. For the ZSM-5-P data in Supplementary Fig. 2, the analysis is from a separate tip of the same individual ZSM-5-P 
a

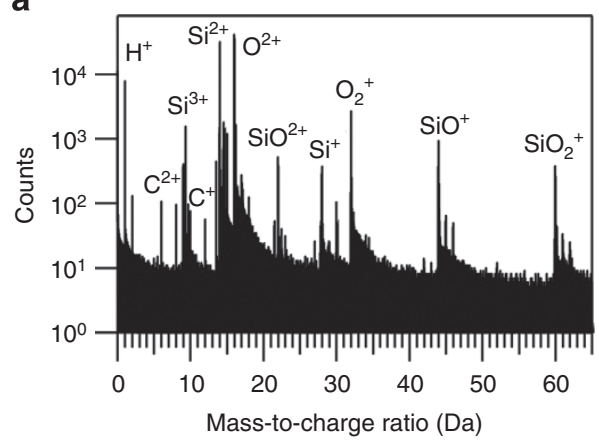

b

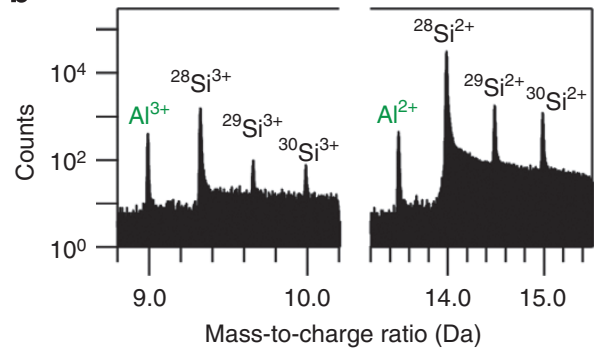

C

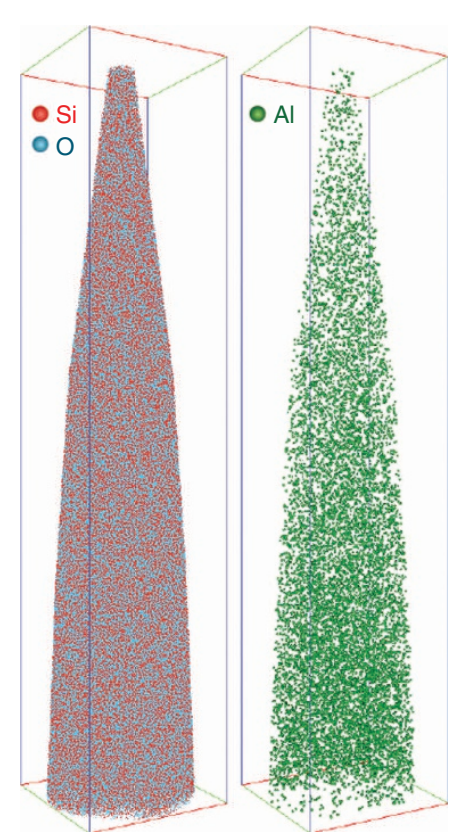

Figure 2 | Detection and homogeneous distribution of individual aluminium atoms in parent ZSM-5-P. (a) Typical APT mass spectrum showing Si and $\mathrm{O}$ and related complex ion mass peaks. (b) Mass spectrum of selected region around the detected $\mathrm{Al}$ peaks. (c,d) 3D atom distribution map of $\mathrm{Si}$ and $\mathrm{O}$ and Al from within a parent zeolite ZSM-5 crystal. Bounding box dimensions are $60 \times 59 \times 298 \mathrm{~nm}^{3}$. Supplementary Movie 1 showing the 3D rotation of $\mathbf{d}$ is available online.

crystal as in Fig. 2, while for the ZSM-5-ST data in Supplementary Fig. 2, the analysis is from a different individual ZSM-5-ST crystal as in Fig. 3.

As can be discerned visually in a $3 \mathrm{D}$ reconstruction of the steam-treated ZSM-5 sample, discrete regions of high $\mathrm{Al}$ concentration are found both distributed evenly in the bulk, as well as segregated along a planar feature highlighted by the black arrow in Fig. 3b. Isolation of a subvolume (Fig. 3d) reveals that the Al distribution within the planar feature occurs as discrete clusters similar to the surrounding material (Fig. 3e). In Fig. 3f, the one-dimensional (1D) composition profile taken from left to right along the red dotted line of Fig. 3d shows an approximately four times higher $\mathrm{Al}$ concentration within the volume of planar feature relative to the surrounding material. We suspect that this planar feature is a grain boundary between two distinct subunits that make up the monolithic coffin-shaped ZSM- 5 crystals, as described by Karwacki et al. ${ }^{20}$. In fact, a slight depletion in the $\mathrm{Al}$ composition is observed adjacent to this planar feature (arrow in Fig. 3f), which supports $\mathrm{Al}$ diffusion to the grain boundary region.

This feature is also observed through scanning transmission electron microscopy (STEM), as illustrated in Fig. 4. Figure 4a shows that at $-25^{\circ}$ the feature appears to be a line. As the specimen is rotated to $-50^{\circ}$ (Fig. $4 \mathrm{~b}$ ) and $-75^{\circ}$ (Fig. 4c), it can be seen that the line is actually made up small, finite clusters. These clusters, and their alignment in one plane, are consistent with the APT results showing the higher concentration of $\mathrm{Al}$ atoms in clusters that align in a plane. The darker contrast in the STEM image is indicative of voids. We postulate that these voids form along the grain boundaries during the steaming process, and the $\mathrm{Al}$ subsequently segregates to these locations.

Statistical analysis of the distribution of Al in ZSM-5 crystals. Using grid-based frequency distribution analyses, the unique 3D nature of the APT data provides an unprecedented means to quantify the atomic-scale distribution of the $\mathrm{Al}$ atoms and the extent of segregation in the as-prepared parent and steam-treated zeolite catalysts.

An isolated subvolume of the steam-treated ZSM-5 sample is shown in Fig. 5a with 2.0\% Al-iso-concentration mesh surfaces encompassing regions enriched in $\mathrm{Al}$, where the volume inside (outside) is greater (less) than $2.0 \% \mathrm{Al}$. The heterogeneous distribution and morphology of the Al-rich regions are easily discerned. A proximity histogram (proxygram) analysis ${ }^{41}$ was performed for each iso-concentration surface in Fig. 5a. The analysis is similar to a $1 \mathrm{D}$ composition profile that follows the contours normal to iso-concentration surface. Figure $5 \mathrm{c}$ shows a proxygram composition profile averaged over all the surfaces shown in Fig. 5a. Over a distance of $\sim 1 \mathrm{~nm}$, the $\mathrm{Al}$ composition increases to $\sim 10 \%$ with a correlated decrease in the $\mathrm{Si}$ composition. While the relative $\mathrm{O}$ composition remains constant, the decrease in Si with increasing Al within the Al-rich regions is expected since $\mathrm{Al}$ substitutes for $\mathrm{Si}$ in the $\mathrm{T}$-sites of the ZSM-5 lattice structure.

To quantify the extent of $\mathrm{Al}$ enrichment, an $\mathrm{Al}-\mathrm{Al}$ nearestneighbour analysis was performed on the experimental $3 \mathrm{D} \mathrm{Al}$ distribution of both parent and steamed ZSM-5 and compared with a randomized $\mathrm{Al}$ distribution ${ }^{42}$. In Fig. 5d,e, the experimental and random $\mathrm{Al}-\mathrm{Al}$ first nearest-neighbour (1NN) distribution is shown for the ZSM-5-P and ZSM-5-ST material, respectively. Little deviation is visually observed between the experimental and random $\mathrm{Al}-\mathrm{Al} 1 \mathrm{NN}$ distribution for the parent ZSM-5 (Fig. 5d), as opposed the steamed ZSM-5 (Fig. 5e). A $\chi^{2}$-statistical test was performed to quantitatively confirm or refute deviation from randomness, while a calculated Pearson coefficient $(\mu)$ was used to compare the relative strength of any deviation $^{42}$. For the $\chi^{2}$-statistical test applied here, the null hypothesis is that the observed distribution is consistent with the expected random distribution. For the parent ZSM-5 in Fig. 5d, an experimental $\chi^{2}=107$ is determined, which is greater than the expected $\chi^{2}=33.9$ with 22 degrees of freedom and a $95 \%$ 
a

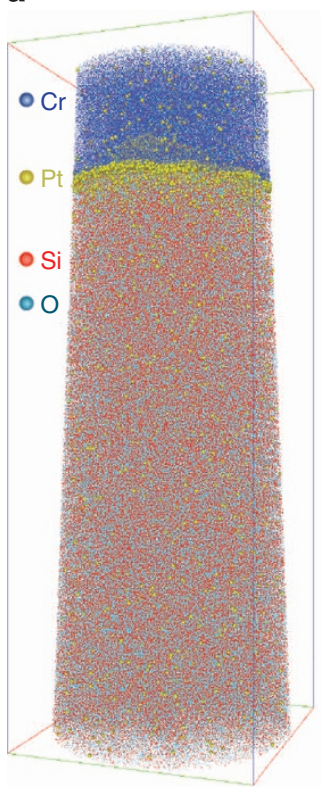

d

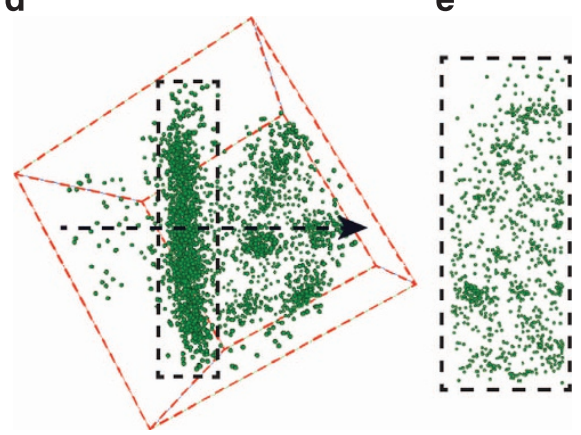

C

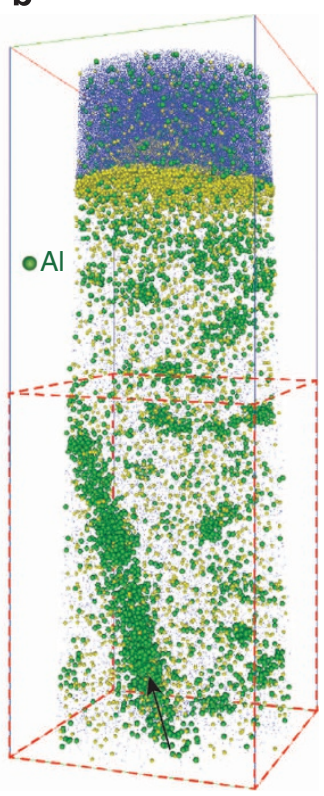

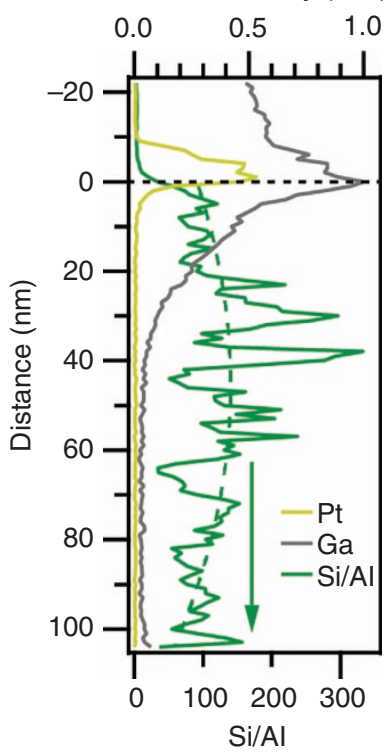

f

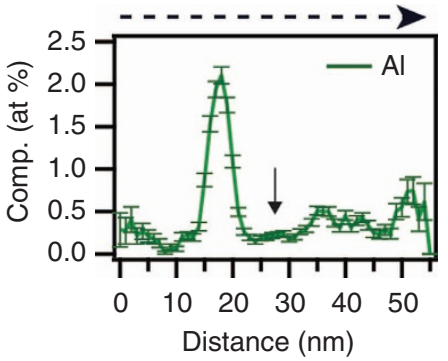

Figure 3 | Detection and heterogeneous distribution of individual aluminium atoms in steamed ZSM-5. (a) Si and O and (b) Al atom distributions from within a steam-treated zeolite ZSM-5 crystal. The $\mathrm{Cr}$ and Pt layers serve as a fiducial to mark the position of the zeolite crystal surface. Bounding box dimensions are $46 \times 45 \times 126 \mathrm{~nm}^{3}$. (c) Si/Al ratio as a function of distance from the surface marked by black dashed line. A least-squares polynomial fit is shown as a green dotted curve to guide the eye to the distribution. The Pt and $\mathrm{Ga}$ intensities as well as the $\mathrm{Si} / \mathrm{Al}$ ratio values are averaged over each crosssection when moving from the top to the bottom of the analysed volume. (d) Al distribution of isolated subvolume (red dashed box) viewed normal to the arrow direction in $\mathbf{b}$. Bounding box dimensions $53 \times 58 \mathrm{~nm}^{2}$. (e) Plane view of the isolated subvolume outlined by dashed box in $\mathbf{d}$. Bounding box dimensions $26 \times 67 \mathrm{~nm}^{2}$. (f) $1 \mathrm{D}$ composition profile with associated error bars taken across the arrowed black dashed line in $\mathbf{d}$. The error bars represent the propagation point counting error as defined in the Methods section. Supplementary Movie 2 showing the 3D rotation of $\mathbf{b}$ is available online.

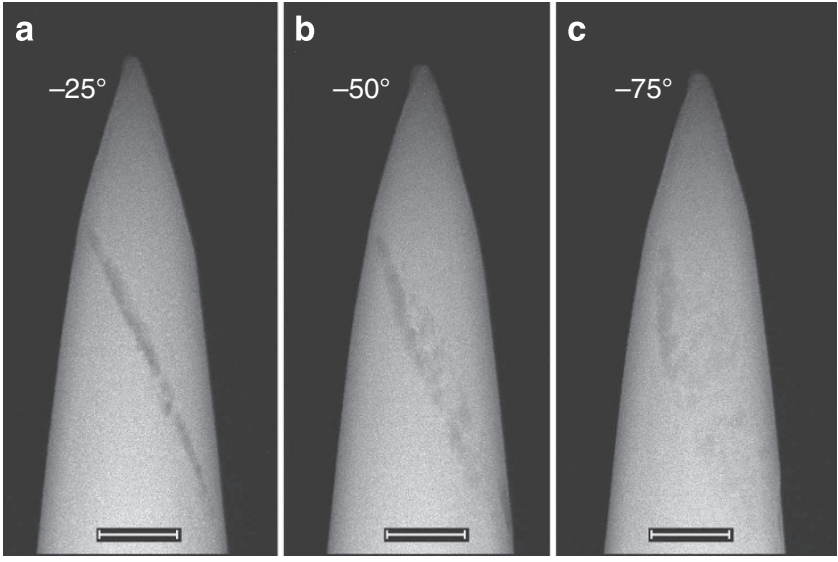

Figure 4 | STEM characterization of a ZSM-5-ST specimen before APT analysis. (a-c) STEM images taken at the three different labelled angles using a tomography holder. Scale bar, $100 \mathrm{~nm}$. confidence level; thus, we reject the null hypothesis and confirm that the experimental $\mathrm{Al}-\mathrm{Al} 1 \mathrm{NN}$ distribution is non-random.

Similarly, we quantitatively confirm a non-random Al-Al $1 \mathrm{NN}$ distribution for the steamed ZSM-5 in Fig. 5e from an experimental $\chi^{2}=2,540$ with the same expected $\chi^{2}=33.9$ and 22 degrees of freedom and a 95\% confidence level. Although both the parent and steamed ZSM-5 Al-Al $1 \mathrm{NN}$ distributions show non-randomness, it is quite obvious that there is a greater departure from randomness for the steamed versus parent specimen. We can determine a relative strength of the randomness by comparing the Pearson coefficient, $\mu$, whose value lies between 0 and 1 , where $\mu=1$ is completely non-random and $\mu=0$ is completely random ${ }^{43}$. With a $\mu_{\text {parent }}=0.7$ and $\mu_{\text {steamed }}=1$, we confirm that there is a much stronger deviation from randomness of the steamed $\mathrm{Al}-\mathrm{Al} 1 \mathrm{NN}$ experimental distribution compared with the parent distribution, which is also qualitatively apparent for the steamed specimen showing obvious regions enriched in $\mathrm{Al}$.

In addition to a greater volume of regions enriched in $\mathrm{Al}$, the steamed ZSM-5 also exhibits a shorter most probable $\mathrm{Al}-\mathrm{Al} 1 \mathrm{NN}$ 
a

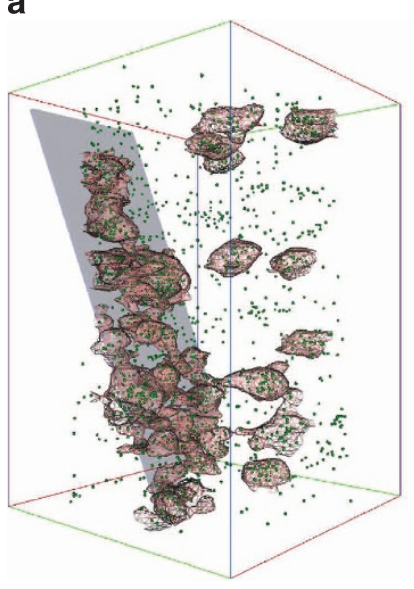

b

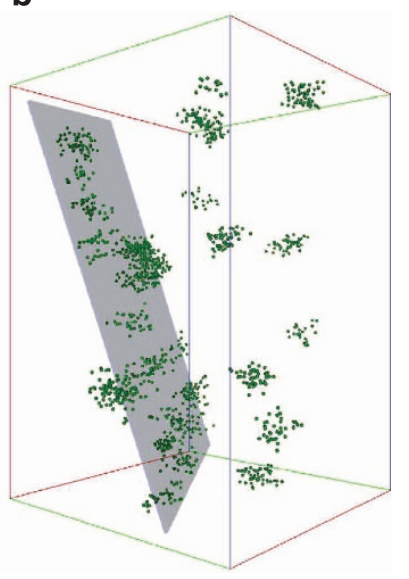

C

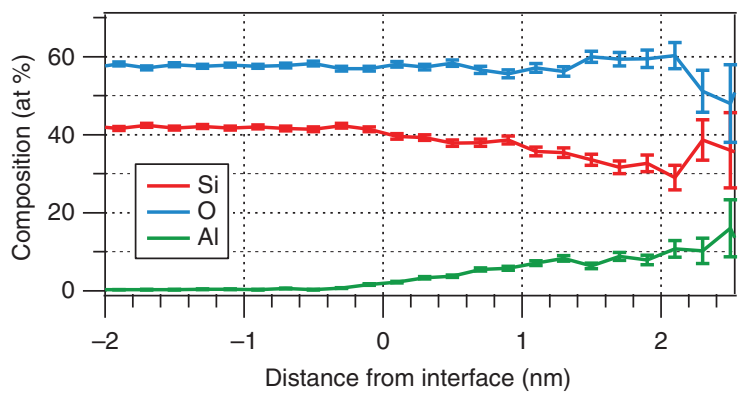

d

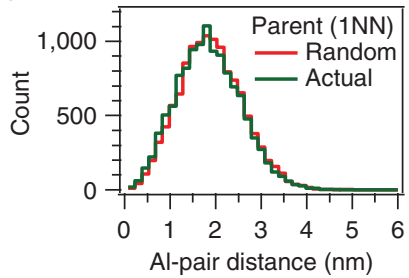

e

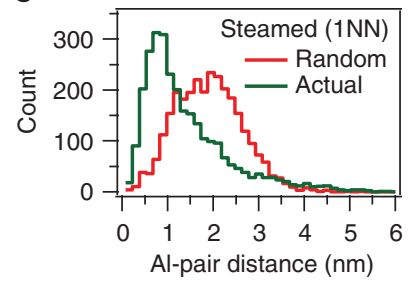

Figure 5 | Quantification of aluminium distribution and clustering in ZSM-5-P and ZSM-5-ST. (a) A selected subvolume of the reconstruction shown in Fig. 3 where only isolated and clustered Al atoms (green) are shown encompassed by $2.0 \%$ Al-iso-concentration surfaces (wire mesh). A semi-transparent plane is shown to highlight the orientation of clusters lying along the grain boundary highlighted in Fig. 3b (arrow). Bounding box dimensions are $46 \times 45 \times 66 \mathrm{~nm}^{3}$. (b) Isolated Al solute atoms belonging to defined clusters; see text. (c) Proximity histogram averaged over all isoconcentration surfaces in $\mathbf{a}$. The error bars represent 1 sigma statistical error of the averaged data set. (d) First Al-Al nearest-neighbour distance distributions in ZSM-5-P and (e) first Al-Al nearest-neighbour distance distributions in ZSM-5-ST.

distance compared with the parent specimen. Fitting the experimental distributions in Fig. 5d,e to a Poisson distribution of the form $P(r)=4 \pi r^{2} q c \exp \left(-\frac{4}{3} \pi q c^{\prime} r^{3}\right)$ adapted from Philippe et $a .^{42}$, where $q=$ detector efficiency $(0.36$ used in the reconstructions) is fixed and $c$ ' is a free parameter related to the atomic density. From the relation $E\left(r^{k}\right)=\int_{0}^{\infty} r^{k} P(r)$, the most probable $1 \mathrm{NN} \mathrm{Al}-\mathrm{Al}$ distance (mode) was calculated from the first moment $(k=1)$ of $E\left(r^{k}\right)$, and s.d. $(\sigma)$ estimated from first and second moments: $\sigma=\sqrt{E\left(r^{2}\right)-E(r)^{2}}$ (ref. 44). For the ZSM-5-P crystal, the mode of the $\mathrm{Al}-\mathrm{Al} 1 \mathrm{NN}$ distance distribution is $18 \pm 6 \AA$, while for the ZSM-5-ST crystal the mode is $9 \pm 3 \AA$.

We note that the co-field evaporation of different phases with different evaporation fields from a heterogeneous material could lead to perturbations in local magnification resulting in the measurement of artificially diffuse distributions ${ }^{45,46}$. However, with respect to the $\mathrm{Al}-\mathrm{Al}$ nearest-neighbour distance distributions reported here, we assert that local magnifications from regions of high $\mathrm{Al}$ content are negligible since $\mathrm{Al}$ does not seem to form distinct precipitates of pure $\mathrm{Al}$ metal or oxide.

To further quantify the Al distribution, a cluster analysis was performed following a method outlined in refs 39,47. The cluster analysis is based on the assumption that the distance between solute (Al) atoms that are clustered together is smaller than the distance when randomly distributed in the matrix. Using a maximum spacing between two $\mathrm{Al}$ atoms of $1.7 \mathrm{~nm}$ and a minimum number of $10 \mathrm{Al}$ atoms defining a cluster, 25 distinct $\mathrm{Al}$ clusters were found in the steamed ZSM-5 sample and are shown in Fig. 5b. We find that the $\mathrm{Al}$ density within the cluster is 20 times greater in the steamed sample at 0.5 atoms $\mathrm{nm}^{-3}$, which corresponds to $2.7 \mathrm{Al}$ atoms per unit cell (UC) (with $\mathrm{UC}_{\mathrm{ZSM}-5}$ taken to be $a=20.00 \AA$, $b=19.99 \AA, c=13.40 \AA)$, compared with 0.025 atoms $\mathrm{nm}^{-3}(0.135$ $\mathrm{Al}$ atoms/UC) for the parent ZSM-5-P material.

\section{Discussion}

In summary, by using the chemically sensitive method of APT for atomic-scale mapping of light elements, it is now possible to obtain unprecedented quantitative insights into the spatial distribution of individual $\mathrm{Al}$ atoms within zeolite crystals, including their $3 \mathrm{D}$ distribution and extent of segregation. It is shown that $\mathrm{Al}$ atoms are non-randomly distributed within the parent zeolite ZSM-5 crystals with a most probable $\mathrm{Al}-\mathrm{Al}$ neighbour distance of $18 \pm 6 \AA$, an average $\mathrm{Al}$ density of 0.025 atoms nm ${ }^{-3}$ and a relative strength of non-randomness of 0.7 measured by the Pearson coefficient of the $\mathrm{Al}-\mathrm{Al} 1 \mathrm{NN}$ distribution. In the severely steam-treated ZSM-5 crystals, the $\mathrm{Al}$ distribution is also non-random where $\mathrm{Al}$ is preferentially located in regions of relatively higher $\mathrm{Al}$ content of $\sim 10$ atoms with an average $\mathrm{Al}$ density of 0.5 atoms $\mathrm{nm}^{-3}$, a most probable $\mathrm{Al}-\mathrm{Al}$ neighbouring distance of $9 \pm 3 \AA$ and a relative strength of non-randomness of 1.0. In addition, the regions of higher $\mathrm{Al}$ density within the steamed specimen were found to be either distributed in discrete patches within the bulk or accumulated within the grain boundaries separating the zeolite building blocks. These grain boundaries, rich in $\mathrm{Al}$ atoms, are proposed to be the highways for $\mathrm{Al}$ transport towards the outer surface of the zeolite crystals.

Our work contains important implications for zeolite-based catalysis because we observe already a non-randomness of the $\mathrm{Al}$ distribution within the highly crystalline parent zeolite specimen, and upon steaming this non-randomness of $\mathrm{Al}$ distribution further develops as a clear long-range redistribution of $\mathrm{Al}$, which leads to further clustering of $\mathrm{Al}$ atoms. This more pronounced clustering especially occurs near regions where molecular diffusion barriers exist suggesting that these barriers, separating the zeolite subunits, act as highways for Al transport towards the outer surface of the zeolite crystals. Clearly, these observations have vast implications for industry-sized zeolite crystals as the porous network acts as highways for $\mathrm{Al}$ transport. Furthermore, we are convinced that the APT method offers a lot of prospect for the characterization of other zeolite-based heterogeneous catalysts currently used in chemical and oil-refining industries, making it a versatile and detailed characterization tool for assessing the processes of zeolite synthesis, steaming and deactivation.

\section{Methods}

Zeolite crystal synthesis and pretreatment. The coffin-shaped large ZSM-5 crystals with a $\mathrm{Si} / \mathrm{Al}$ ratio of 17 were synthesized from the following raw materials: Ludox AS40, tetrapropylammonium (TPA) bromide (TPABr, Fluka),

$\mathrm{Al}_{2}\left(\mathrm{SO}_{4}\right)_{3} \cdot 18 \mathrm{H}_{2} \mathrm{O}$ (Baker) and $\mathrm{NH}_{4} \mathrm{OH}(29 \%)$. The molar composition was 6.65 
$\left(\mathrm{NH}_{4}\right)_{2} \mathrm{O} / 0.67 \mathrm{TPA}_{2} \mathrm{O} / 0.025 \mathrm{Al}_{2} \mathrm{O}_{3} / 10 \mathrm{SiO}_{2} / 121 \mathrm{H}_{2} \mathrm{O}$. For synthesis, Ludox AS40 and TPABr were mixed. Subsequently, $\mathrm{Al}_{2}\left(\mathrm{SO}_{4}\right)_{3} \cdot 18 \mathrm{H}_{2} \mathrm{O}$ was added and mixed for $5 \mathrm{~min}$, followed by the addition of $\mathrm{NH}_{4} \mathrm{OH}$ and further mixing for $7 \mathrm{~min}$. Heating was carried out over $2 \mathrm{~h}$ to $453 \mathrm{~K}$ ( 7 days soak time under static conditions), followed by washing and drying at $393 \mathrm{~K}$ for $12 \mathrm{~h}$.

Before the steaming post-treatment, the crystals were calcined at $823 \mathrm{~K}$ $\left(5 \mathrm{~K} \mathrm{~min}^{-1}, 8 \mathrm{~h}\right.$ ) followed by triple ion exchange with a $10 \mathrm{wt} \%$ ammonium nitrate (>99\%, Acros Organic) solution at $353 \mathrm{~K}$. Then, the material was calcined at $773 \mathrm{~K}$ $\left(2 \mathrm{~K} \mathrm{~min}^{-1}, 6 \mathrm{~h}\right)$ to release the ammonia attached to the acid sites. The sample after this treatment is denoted as parent ZSM-5-P. Before starting the dealumination post-treatment, the zeolite crystals were preheated to $393 \mathrm{~K}$ for $60 \mathrm{~min}$ in a quartz tubular oven (Thermoline 79300) at a rate of $5 \mathrm{~K} \mathrm{~min}^{-1}$. The zeolite crystals contained inside the tubular oven were then heated to $973 \mathrm{~K}$ at a rate of $5 \mathrm{~K} \mathrm{~min}^{-1}$ and steamed using a water $(373 \mathrm{~K})$ saturated $\mathrm{N}_{2}$ flow $\left(140 \mathrm{ml} \mathrm{min}^{-1}\right)$ for $300 \mathrm{~min}$. After the steaming post-treatment, the zeolite crystals were calcined at $773 \mathrm{~K}$ $\left(5 \mathrm{Kmin}^{-1}, 6 \mathrm{~h}\right)$ and this sample is named steamed ZSM-5-ST.

Zeolite crystal characterization and related analysis. The two batches of prepared zeolite crystals were imaged using a Zeiss Orion Helium Ion Microscope. An FEI Helios 600 dual-beam FIB/SEM was used to image and prepare the specimens on Si micropost arrays for APT analysis. A 30-kV Ga-ion beam was used to trench and cut the lamella and annular mill into the needle shape. A final low $2 \mathrm{kV}$ shower over the tip was used to remove most of the remaining $\mathrm{Pt} / \mathrm{C}$ cap and remove deep surface damage from the $30 \mathrm{kV}$ beam. Microfabricated Si micropost arrays for APT analysis are commercially available from the Atom Probe Tomography division of Cameca Instruments. For a more detailed description of the FIB-based specimen preparation procedure, we refer the reader to the work of Thompson et al. ${ }^{40}$. Following FIB fabrication, a thin Cr metal film was deposited on the specimens using a South Bay Technologies IBS/e deposition system, which included simultaneous specimen rotation and tilting to ensure the conformal coating of all the needle specimens. Qualitatively, we found that APT analysis yield increased with $\sim 10-30 \mathrm{~nm} \mathrm{Cr}$ coating. A LEAP $\times 4000 \mathrm{HR}$ local electrode APT system from CAMECA Instruments was used to map the atomic composition of individual zeolite specimens. The following parameters were used for both ZSM-5-P and ZSM-5-ST-laser energy $=200 \mathrm{pJ}$, detection rate $=0.2 \%$ and temperature $=44 \mathrm{~K}$.

The tomographic reconstructions and analysis, including nearest-neighbour and cluster analyses, were performed with an $x=1.0 \mathrm{~nm}(3.0 \mathrm{~nm}), y=1.0 \mathrm{~nm}$ $(3.0 \mathrm{~nm}), z=1.0 \mathrm{~nm}(1.5 \mathrm{~nm})$ voxel grid size (delocalization) using Cameca's Integrated Visualization \& Analysis Software (IVAS) version 3.6.6. IVAS was also used for the cluster analysis with parameters $D_{\max }=1.7 \mathrm{~nm}$ and $N_{\min }=10$. For the nearest-neighbour analysis, the expected nearest-neighbour distribution (random) was determined from a simulated random distribution of the same solute composition and reconstructed dimensions. The error bars for the $1 \mathrm{D}$ composition profiles reported throughout represent the propagation point counting error as $E=\sqrt{\frac{C_{i}\left(1-C_{i}\right)}{N}}$ where $C_{i}=\left(x_{i} / N\right), x_{i}$ is the number of $i$ solute ions and $N$ is the total number of counts within the given bin. The error in the $1 \mathrm{NN}$ distances is reported as 1 s.d. The most probable distance, mode, of the $\mathrm{Al}-\mathrm{Al} 1 \mathrm{NN}$ distribution was determined from distance corresponding to the value of greatest probability. When possible, a comparison of both before and post SEM images were used to estimate the volume of evaporated material and guide the choice of reconstruction parameters to obtain a reconstruction of reasonable volume (see Fig. 1f,g and Supplementary Fig. 3). For a more detailed description of atom probe analysis and data reconstruction and analysis using a LEAP, please refer to the published user's guide $^{39}$.

\section{References}

1. Hunger, M. in Zeolites and Catalysis: Synthesis, Reactions, and Applications. (eds Čejka, J., Corma, A. \& Zones, S. ) 493-546 (Wiley-VCH, 2010).

2. Kramer, G. J. \& Van Santen, R. A. Theoretical determination of proton affinity differences in zeolites. J. Am. Chem. Soc. 115, 2887-2897 (1993).

3. Groen, J. C. et al. Creation of hollow zeolite architectures by controlled desilication of Al-zoned ZSM-5 crystals. J. Am. Chem. Soc. 127, 10792-10793 (2005).

4. Van Bokhoven, J. A., Koningsberger, D. C., Kunkeler, P., van Bekkum, H. \& Kentgens, A. P. M. Stepwise dealumination of zeolite beta at specific T-sites observed with ${ }^{27} \mathrm{Al}$ MAS and ${ }^{27} \mathrm{Al}$ MQ MAS NMR. J. Am. Chem. Soc. 122, 12842-12847 (2000).

5. Van Bokhoven, J. A. \& Danilina, N. in Zeolites and Catalysis: Synthesis, Reactions, and Applications. (eds Čejka, J., Corma, A. \& Zones, S.) 283-300 (Wiley-VCH, 2010).

6. Bellussi, G., Carati, A. \& Millini, R. in Zeolites and Catalysis: Synthesis, Reactions, and Applications. (eds Čejka, J., Corma, A. \& Zones, S.) 449-491 (Wiley-VCH, 2010).

7. Corma, A. in Studies in Surface Science and Catalysis. (eds Jacobs, P.A. \& van Santen, R.A.) 49-67 (Elsevier, 1989).

8. Lercher, J. A. \& Jentys, A. in Handbook of Porous Solids. (eds Schuth, F., Sing, K.S. \& Weitkamp, J.) 1097-1156 (Wiley-VCH, 2002).
9. Kokotailo, G. T., Lawton, S. L., Olson, D. H., Olson, D. H. \& Meier, W. M. Structure of synthetic zeolite ZSM-5. Nature 272, 437-438 (1978).

10. Olson, D. H., Kokotailo, G. T., Lawton, S. L. \& Meier, W. M. Crystal-structure and structure-related properties of ZSM-5. J. Phys. Chem. 85, 2238-2243 (1981)

11. Van Koningsveld, H., Jansen, J. C. \& Van Bekkum, H. The monoclinic framework structure of zeolite H-ZSM-5. Comparison with the orthorhombic framework of as-synthesized ZSM-5. Zeolites 10, 235-242 (1990).

12. Heo, N. H. et al. Detailed determination of the $\mathrm{Tl}+$ positions in zeolite $\mathrm{Tl}-$ ZSM-5. Single-crystal structures of fully dehydrated Tl-ZSM-5 and H-ZSM-5 (MFI, Si/Al = 29). Additional evidence for a nonrandom distribution of framework aluminum. J. Phys. Chem. C 113, 19937-19956 (2009).

13. Olson, D. H., Khosrovani, N., Peters, A. W. \& Toby, B. H. Crystal structure of dehydrated Cs-ZSM-5 (5.8Al): evidence for nonrandom aluminum distribution. J. Phys. Chem. B 104, 4844-4848 (2000).

14. Han, O. H., Kim, C. S. \& Hong, S. B. Direct evidence for the nonrandom nature of $\mathrm{Al}$ substitution in zeolite ZSM-5: an investigation by ${ }^{27} \mathrm{Al}$ MAS and MQ MAS NMR. Angew. Chem. Int. Ed. 41, 469-472 (2002).

15. Sklenak, S. et al. Aluminum siting in silicon-rich zeolite frameworks: a combined high-resolution ${ }^{27} \mathrm{Al} \mathrm{NMR}$ spectroscopy and quantum mechanics/molecular mechanics study of ZSM-5. Angew. Chem. Int. Ed. 46, 7286-7289 (2007).

16. Vjunov, A. et al. Quantitatively probing the Al distribution in zeolites. J. Am. Chem. Soc. 136, 8296-8306 (2014).

17. Althoff, R., Schulzdobrick, B., Schuth, F. \& Unger, K. Controlling the spatial-distribution of aluminum in ZSM-5 crystals. Microporous Mater. 1, 207-218 (1993).

18. Chao, K. J. \& Chern, J. Y. Aluminum distribution in large ZSM-5 crystals. Zeolites 8, 82-85 (1988).

19. Danilina, N., Krumeich, F., Castelanelli, S. A. \& van Bokhoven, J. A. Where are the active sites in zeolites? Origin of aluminum zoning in ZSM-5. J. Phys. Chem. C 114, 6640-6645 (2010).

20. Karwacki, L. et al. Morphology-dependent zeolite intergrowth structures leading to distinct internal and outer-surface molecular diffusion barriers. Nat. Mater. 8, 959-965 (2009).

21. Ristanovic, Z. et al. Intergrowth structure and aluminium zoning of a zeolite ZSM- 5 crystal as resolved by synchrotron-based micro X-ray diffraction imaging. Angew. Chem. Int. Ed. 52, 13382-13386 (2013).

22. Vonballmoos, R. \& Meier, W. M. Zoned aluminum distribution in synthetic zeolite ZSM-5. Nature 289, 782-783 (1981).

23. deLucas, A., Canizares, P., Duran, A. \& Carrero, A. Dealumination of HZSM-5 zeolites: effect of steaming on acidity and aromatization activity. Appl. Catal. A: Gen. 154, 221-240 (1997).

24. Beyerlein, R. A., ChoiFeng, C., Hall, J. B., Huggins, B. J. \& Ray, G. J. Effect of steaming on the defect structure and acid catalysis of protonated zeolites. Top. Catal. 4, 27-42 (1997).

25. Lago, R. M. in Studies in Surface Science and Catalysis. (eds Murakami, Y., Iijima, A. \& Ward, J.W.) 677-684 (Elsevier, 1986).

26. Lonyi, F. \& Lunsford, J. H. The development of strong acidity in hexafluorosilicate-modified Y-type zeolites. J. Catal. 136, 566-577 (1992).

27. Mafra, L. \& Klinowski, J. Advanced solid-state NMR techniques for the study of molecular sieves (John Wiley \& Sons Ltd, 2013).

28. Joyner, R. W., Smith, A. D., Stockenhuber, M. \& van den Berg, M. W. E. The local structure of aluminium sites in zeolites. Phys. Chem. Chem. Phys. 6, 5435-5439 (2004).

29. van Bokhoven, J. A., Koningsberger, D. C., Kunkeler, P. \& van Bekkum, H. Influence of steam activation on pore structure and acidity of zeolite beta: an Al K-edge XANES study of aluminum coordination. J. Catal. 211, 540-547 (2002).

30. van Bokhoven, J. A., Sambe, H., Ramaker, D. E. \& Koningsberger, D. C. Al $\mathrm{K}$-edge near-edge X-ray absorption fine structure (NEXAPS) study on the coordination structure of aluminum in minerals and Y zeolites. J. Phys. Chem. B 103, 7557-7564 (1999).

31. van Bokhoven, J. A., van der Eerden, A. M. J. \& Koningsberger, D. C. Threecoordinate aluminum in zeolites observed with in situ X-ray absorption nearedge spectroscopy at the $\mathrm{Al} \mathrm{K-edge:} \mathrm{flexibility} \mathrm{of} \mathrm{aluminum} \mathrm{coordinations} \mathrm{in}$ zeolites. J. Am. Chem. Soc. 125, 7435-7442 (2003).

32. van Bokhoven, J. A., van der Eerden, A. M. J. \& Prins, R. Local structure of the zeolitic catalytically active site during reaction. J. Am. Chem. Soc. 126, 4506-4507 (2004).

33. van Bokhoven, J. A. et al. Determining the aluminium occupancy on the active T-sites in zeolites using X-ray standing waves. Nat. Mater. 7, 551-555 (2008).

34. Aramburo, L. R. et al. X-ray Imaging of zeolite particles at the nanoscale: influence of steaming on the state of aluminum and the methanol-to-olefin reaction. Angew. Chem. Int. Ed. 51, 3616-3619 (2012).

35. Aramburo, L. R. et al. 3D nanoscale chemical imaging of the distribution of aluminum coordination environments in zeolites with soft X-ray microscopy. ChemPhysChem 14, 496-499 (2013).

36. Aramburo, L. R. et al. The porosity, acidity, and reactivity of dealuminated zeolite ZSM-5 at the single particle level: the influence of the zeolite architecture. Chem. Eur. J. 17, 13773-13781 (2011). 
37. Collignon, F., Jacobs, P. A., Grobet, P. \& Poncelet, G. Investigation of the coordination state of aluminum in beta zeolites by X-ray photoelectron spectroscopy. J. Phys. Chem. B 105, 6812-6816 (2001).

38. Miller, M. K. \& Forbes, R. G. Atom probe tomography. Mater. Charact. 60, 461-469 (2009).

39. Larson, D. J., Prosa, T. J., Ulfig, R. M., Geiser, B. P. \& Kelly, T. F. Local Electrode Atom Probe Tomography: A User's Guide (Spinger, 2013).

40. Thompson, K. et al. In situ site-specific specimen preparation for atom probe tomography. Ultramicroscopy 107, 131-139 (2007).

41. Hellman, O. C., Vandenbroucke, J. A., Rusing, J., Isheim, D. \& Seidman, D. N. Analysis of three-dimensional atom-probe data by the proximity histogram. Microsc. Microanal. 6, 437-444 (2000).

42. Philippe, T. et al. Clustering and nearest neighbour distances in atom-probe tomography. Ultramicroscopy 109, 1304-1309 (2009).

43. Moody, M. P., Stephenson, L. T., Ceguerra, A. V. \& Ringer, S. P. Quantitative binomial distribution analyses of nanoscale like-solute atom clustering and segregation in atom probe tomography data. Microsc. Res. Techniq. 71, 542-550 (2008).

44. Philippe, T., Duguay, S., Grancher, G. \& Blavette, D. Point process statistics in atom probe tomography. Ultramicroscopy 132, 114-120 (2013).

45. Devaraj, A., Colby, R., Vurpillot, F. \& Thevuthasan, S. Understanding atom probe tomography of oxide-supported metal nanoparticles by correlation with atomic-resolution electron microscopy and field evaporation simulation. J. Phys. Chem. Lett. 5, 1361-1367 (2014).

46. Vurpillot, F., Bostel, A. \& Blavette, D. Trajectory overlaps and local magnification in three-dimensional atom probe. Appl. Phys. Lett. 76, 3127-3129 (2000).

47. Gault, B., Moody, M. P., Cairney, J. M. \& Ringer, S. P. Atom Probe Microscopy (Springer, 2012).

\section{Acknowledgements}

The APT experiments in this study were performed under a science theme user proposal at EMSL, a national scientific user facility sponsored by the Department of Energy's Office of Biological and Environmental Research and located at Pacific Northwest National Laboratory. I.A. acknowledges support through the LDRD programme at PNNL. PNNL is operated by Battelle for the U.S. Department of Energy under contract
DE-AC05-76RL01830. B.M.W. acknowledges financial support from the Netherlands Organisation for Scientific Research (NWO) Gravitation Program (Netherlands Center for Multiscale Catalytic Energy Conversion, MCEC) and a TOP NWO-CW Grant, as well as a European Research Council (ERC) Advanced Grant (321140). We acknowledge Machteld Mertens (ExxonMobil) for making the zeolite ZSM-5 crystals.

\section{Author contributions}

D.E.P. performed the APT experiments, developed the applied statistical analysis and analysed the APT data under the guidance of S.R.B. and B.M.W., while I.A. was involved in the APT experiments, including its analysis and performed the STEM experiments. L.K. performed the TEM measurements leading to Supplementary Fig. 1. J.L. and B.W.A. helped D.E.P. with the APT experiments, while Z.R. prepared the parent and steamed zeolite crystals. J.A.L. was involved in the initial discussions of the APT experiments. All authors contributed to the discussion and manuscript preparation. S.R.B. and B.M.W. directed the research.

\section{Additional information}

Supplementary Information accompanies this paper at http://www.nature.com/ naturecommunications

Competing financial interests: The authors declare no competing financial interests.

Reprints and permission information is available online at http://npg.nature.com/ reprintsandpermissions/

How to cite this article: Perea, D. E. et al. Determining the location and nearest neighbours of aluminium in zeolites with atom probe tomography. Nat. Commun. 6:7589 doi: $10.1038 /$ ncomms8589 (2015).

This work is licensed under a Creative Commons Attribution 4.0 International License. The images or other third party material in this article are included in the article's Creative Commons license, unless indicated otherwise in the credit line; if the material is not included under the Creative Commons license, users will need to obtain permission from the license holder to reproduce the material. To view a copy of this license, visit http://creativecommons.org/licenses/by/4.0/ 